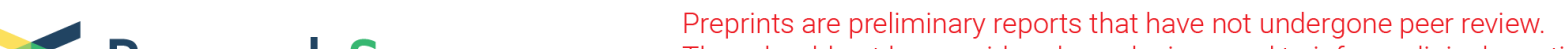 $\begin{array}{ll}\text { Research Square } & \begin{array}{l}\text { They should not be considered conclusive, used to inform clinical practice, } \\ \text { or referenced by the media as validated information. }\end{array}\end{array}$
}

\section{A High-Throughput Screening Method for Endophytic Bacteria With Antagonistic Activity Against Magnaporthe Oryzae in Rice (Oryza Sativa L.) Seeds}

\section{Zhishan Wang}

USTB: University of Science and Technology Beijing

\section{Xianyu Wu}

USTB: University of Science and Technology Beijing

Ni Li

Hunan Hybrid Rice Resrach Center

\section{Weiping Wang}

Hunan Hybrid Rice Research Center

Yang Liu (D ly81150@163.com )

University of Science and Technology Beijing https://orcid.org/0000-0003-3261-7243

\section{Short Report}

Keywords: Rice seed, Endophytic bacteria, High-throughput screening, Magnaporthe oryzae, Antagonistic activity

Posted Date: September 15th, 2021

DOl: https://doi.org/10.21203/rs.3.rs-876024/v1

License: (c) (i) This work is licensed under a Creative Commons Attribution 4.0 International License.

Read Full License

Version of Record: A version of this preprint was published at Plant Growth Regulation on November 10th, 2021. See the published version at https://doi.org/10.1007/s10725-021-00771-z. 


\section{Abstract}

Screening for microorganisms with antagonistic activity against pathogens in crops is of great significance for the preparation of microbial antagonists, the control of crop diseases, and the sustainable development of agriculture. Through the experiment, a rapid, efficient, and one-step highthroughput method for screening endophytic bacteria with antagonistic activity against Magnaporthe oryzae in rice seeds was successfully established, and the experimental results showed that the endophytic bacteria with antagonistic activity of Magnaporthe oryzae ACCC 36020 could be directly screened from six groups of experimental samples by this method. The establishment of this method can achieve simultaneous screening and purification, one-step high-throughput screening of antagonistic bacteria in rice seeds, and greatly save time.

\section{Introduction}

Rice blast caused by M. oryzae is a worldwide rice disease, which causes a huge loss of rice yield every year (Feng et al. 2019). The control of rice blast is mainly through the use of fungicides, strengthening field management, breeding disease-resistant varieties, and biological methods. However, it has been proved that increasing the use of fungicides or rice varieties resistant to rice blast under field conditions is ineffective for long-term control of rice blast (Deng and Naqvi 2019). And the excessive use of fungicides and pesticide residues pose a major threat to food safety and the environment and are likely to cause drug resistance for pathogens and thus form unpredictable ecological risks. Therefore, the search for a new type of safe, environment-friendly, cost-effective fungicide against $M$. oryzae has become a key problem to be solved in rice production. Fungicides prepared by microorganisms with antagonistic activity against pathogenic fungi are more green, environmentally friendly, and safe biological control methods. And it is particularly important to isolate and screen microbial resources with antifungal activity from rice tissues or the environment. At present, the most commonly used methods for screening microorganisms with antibacterial activity in plants are the plate confrontation method (Jing et al. 2020; Degani and Dor 2021) and the Oxford cup method (Sun et al. 2018).

As a kind of microbial resource living in the tissues or organs of healthy plants in a certain stage or all stages, plant endophytes have become potential microbial pesticides, production-increasing bacteria or potential biocontrol carrier bacteria in biological control (de Almeida Lopes et al. 2018; Huang et al. 2021). Studies have shown that endophytic bacteria isolated from plant seeds have a strong antagonistic effect on plant pathogens and can be used to prepare microbial agents for the control of plant diseases (Shehata et al. 2017; Khalaf and Raizada 2018; Rangjaroen et al. 2019; Matsumoto et al. 2021). And endophytic bacteria isolated from rice seeds also showed strong antagonism against $M$. oryzae (Jing et al. 2020). Therefore, screening an endophytic bacterium with strong antagonistic activity against the pathogen of rice blast from rice seeds is of great significance for the biological control of rice blast.

However, these methods for screening microorganisms with antagonistic activity against pathogenic fungi in plants, including plate confrontation method and Oxford cup method, need to be based on the 
integration of separate culture, purification, and screening, not only the synchronous growth and coordination between different strains need to be maintained, but also the operation is troublesome, the cycle is long, the flux is low. To screen endophytic bacteria with antagonistic activity against pathogenic fungi in rice seeds, it is usually necessary to select the rice seed samples from the areas where pathogenic microorganisms occur frequently, and after obtaining single bacteria from the seeds, but also need to go through purification and plate confrontation test to finally determine the target strain. This process not only consumes a lot of time and energy, but also is very inefficient. In order to realize efficient and high-throughput screening of endophytic bacteria with antagonistic fungal activity in rice seeds, we selected 6 rice varieties with different resistance to rice blast as materials and finally established a highthroughput screening method for endophytic bacteria with the antagonistic activity of $M$. oryzae in rice seeds through experiments.

\section{Materials And Methods}

The source of rice seeds and M. oryzae

The six rice seed samples were provided by Hunan Hybrid Rice Research Center, and the related information of all samples is shown in Table 1. All the seed samples were collected and selected over the years and preserved in Changsha Comprehensive Test Base of Hunan Hybrid Rice Research Center. Then the samples were transferred to sterile bags, sealed, and stored at $4{ }^{\circ} \mathrm{C}$ until used (It can be preserved for a long time in a sealed environment).

Table 1

Statistical table of information on rice seed samples

\begin{tabular}{|lllll|}
\hline $\begin{array}{l}\text { Sample } \\
\text { ID }\end{array}$ & Variety names & Rice blast resistance & $\begin{array}{l}\text { Rice blast } \\
\text { resistance } \\
\text { gene }\end{array}$ & Source \\
\hline RBR01 & R900 & High infection & -- & $\begin{array}{l}\text { Parents of super hybrid } \\
\text { rice }\end{array}$ \\
\hline RBR02 & W1404 & High resistance & Pigm & Restorer line \\
\hline RBR03 & C_liangyou_557 & Moderate resistance & Pi2 & $\begin{array}{l}\text { Hybrid breeding of } \\
\text { C815S and R557 }\end{array}$ \\
\hline RBR04 & R1137 & Resistance & Pi2 & $\begin{array}{l}\text { Hybrid breeding of R900 } \\
\text { and Wushansimiao }\end{array}$ \\
\hline RBR05 & Y_liangyou_1137 & $\begin{array}{l}\text { Moderate resistance } \\
\text { /Moderate infection }\end{array}$ & Pi2 & $\begin{array}{l}\text { Hybrid breeding of Y58S } \\
\text { and R1137 }\end{array}$ \\
\hline RBR06 & Xingliangyou_1283 & $\begin{array}{l}\text { Moderate infection } \\
\text { Hybrid breeding of }\end{array}$ \\
\hline
\end{tabular}

M. oryzae is the pathogenic strain of rice blast, the strain M. oryzae ACCC 36020 used in this study was provided by Professor Xiaoxia Zhang at Agricultural Culture Collection of China (ACCC), and it is a clearly 
documented pathogen strain that can cause rice blast (in Strain Catalogue of ACCC).

\section{Sample surface sterilization and treatment}

The surface sterilization of rice seeds was mainly accomplished by sterile water and alcohol, and the specific steps were as follows: weighed one gram of rice seeds and washed with sterile water to remove impurities such as dust on the seed surface; transferred the seeds to alcohol and soaked for about 30 seconds; washed the seeds again with sterile water for six times to thoroughly wash away the alcohol remaining on the surface of the sample, so as not to affect the follow-up experiments. To validate that the surface was sterilized, sterile tweezers were used to press surface-sterilized seeds into LB medium (LUQIAO), and the samples were incubated at $32^{\circ} \mathrm{C}$ for $72 \mathrm{~h}$.

\section{Enrichment culture of endophytic bacteria in rice seeds}

Put the surface-sterilized seeds in a sterile mortar and ground them into powder. Then put an appropriate amount of powder in $1.5 \mathrm{~mL}$ aseptic centrifuge tubes and added one milliliter LB liquid medium (LUQIAO). All samples were cultured at $32^{\circ} \mathrm{C}$ for $8-12 \mathrm{~h}$ to enrich endophytic bacteria.

Activation of M. oryzae

M. oryzae stored in the test tube was picked up by an inoculation needle and inoculated on PDA solid medium (Acmec) and activated at $28^{\circ} \mathrm{C}$. Then collect the spores and add sterile water, and the spore suspension of $M$. oryzae was prepared by re-suspending at least $30 \mathrm{~min}$ in a shaker at $28^{\circ} \mathrm{C}$.

Screening of endophytic bacteria with antagonistic activity against M. oryzae

Firstly, the LB solid medium was sterilized at $121^{\circ} \mathrm{C}$, and the spore suspension of $M$. oryzae was added (200-300 $\mu \mathrm{L}$ spore suspension / $100 \mathrm{~mL}$ LB medium, the concentration can be adjusted according to the specific experimental conditions) when the temperature was not too hot $\left(50-60^{\circ} \mathrm{C}\right)$. And quickly poured the mixture into the petri dish and waited for it to solidify. Secondly, the sample culture medium after enrichment culture was diluted to $10^{-5}$ and $10^{-6}$ with aseptic water, and after mixing, $120-150 \mu \mathrm{L}$ was absorbed by pipettor and coated on the solidified LB medium plate mixed with $M$. oryzae. Then all the samples were cultured at $32^{\circ} \mathrm{C}$ for one or two days. Finally, the existence of endophytic bacteria with antagonistic activity against $M$. oryzae in the rice seeds of this variety was determined by observing whether there were transparent circles on the plate, and the diameter of the transparent circle reflected the antagonistic activity of the endophytic bacteria.

\section{Results And Discussion}

The experimental results showed that the endophytic bacteria with the activity for resistance to M. oryzae ACCC 36020 were successfully screened from the six varieties of rice seed samples after using the experimental method we designed (Fig. 1 and Fig. 2). Among them, the RBR04 sample screened the most endophytic bacteria, while the other five groups only had one or two transparent circles (Fig. 2). Although 
the number of endophytic bacteria with antifungal activity was small in each rice variety, these experimental data provide direct evidence for the feasibility for high-throughput screening of endophytic bacteria with antagonistic activity against pathogenic fungi in rice seeds.

The screening rate of bacteria with antagonistic activity against corresponding pathogenic fungi generally has a great relationship with the species and concentration of endophytic bacteria inherent in the sample itself. To increase the screening rate of the target strains, we selected the rice varieties with resistance to rice blast, and also enriched the endophytic bacteria in the seed samples to avoid failure due to too few endophytic bacteria or too low concentration in the samples. In the past, our research group used traditional methods to screen and explore the endophytic bacteria with antagonistic activity against pathogenic fungi in plant seeds, and the entire experimental process took at least one week or more (Jing et al. 2020; Yang et al. 2020). By consulting the method description in other related reports, we can also find that it takes a long time from strain screening to the completion of antagonistic experiments (Liu et al. 2016; de Almeida Lopes et al. 2018; Rangjaroen et al. 2019; Rong et al. 2020; Tian et al. 2020). Compared with the traditional strain screening and plate confrontation experiment, the onestep high-throughput screening method for endophytic bacteria with antagonistic activity against pathogenic fungi in rice seeds can complete all the work in four or five days. Therefore, the method for high-throughput screening of endophytic bacteria with antagonistic fungal activity in rice seeds realized the combination for the screening of bacteria and the antagonistic experiment and greatly improved the efficiency of the experiment. In the process of the experiment, in addition to the methods involved in this experiment, we also tried other experiments. To shorten the time as much as possible, we chose to mix the seed grinding dilution solution with fungal spore suspension in a certain proportion and then spread it directly on LB medium or PDA medium. However, we failed probably because the concentration of endophytic bacteria with antifungal activity in the seed samples was too low. We speculate that if the species and concentration of bacteria with antifungal activity in the sample are very high, we may directly screen the target strain in a shorter time.

Although the experimental method designed in this experiment is only aimed at the high-throughput screening of endophytic bacteria resistant to M. oryzae in rice seeds, by adjusting the experimental scheme, it is also suitable for high-throughput screening of endophytic bacteria with anti-pathogenic fungal activity in corn, sorghum, wheat and other plant seeds, which shows that this method has certain universality and broad application prospects. In the future, the research on endophytic bacteria in plant seeds will mainly focus on the characteristics of high yield, high quality, and multi-resistance of plant, and the identification and screening of endophytic growth-promoting bacteria and endophytic antagonistic bacteria in plant seeds is a very important link. In order to achieve efficient and rapid screening of endophytic bacteria with antifungal activity in plant seeds, one-step high-throughput screening methods are undoubtedly the development trend in this field. Through this article, we also hope that we can provide researchers with one more method to choose in the future when screening endophytic bacteria with antagonistic fungal activity in plant seeds, to improve the efficiency as much as possible. 


\section{Declarations}

\section{Acknowledgments}

The research was supported by the Fundamental Research Funds for the Central Universities (No. FRFTP-20-044A2; FRF-BR-19-003B; FRF-BR-20-03B; FRF-MP-20-39) and the Open Research Fund of State Key Laboratory of Hybrid Rice (Hunan Hybrid Rice Research Center) (No. 2017KF04).

\section{Authors' Contributions}

Wang ZS and Wu XY designed and participated in all experimental procedures, performed data analysis, and drafted the manuscript. Li N participated in the samples collection, preparation, and cultivation. Wang WP and Liu Y supervised the study and critically revised the manuscript. All authors read and approved the final manuscript.

\section{Availability of Data and Materials}

All data generated or analyzed during this study are included in this published article.

\section{Ethics Approval and Consent to Participate}

Not applicable.

\section{Consent for Publication}

Not applicable.

\section{Compliance with ethical standards}

This article does not contain any studies with human participants or animals performed by any of the authors.

\section{Conflict of interest}

The authors declare that they have no competing interests.

\section{References}

1. de Almeida Lopes KB, Carpentieri-Pipolo V, Fira D, Balatti PA, López SMY, Oro TH, Stefani Pagliosa E, Degrassi $G$ (2018) Screening of bacterial endophytes as potential biocontrol agents against soybean diseases. J Appl Microbiol 125(5): 1466-1481. https://doi. org/10.1111/jam.14041

2. Degani O, Dor S (2021) Trichoderma biological control to protect sensitive maize hybrids against late wilt disease in the field. J Fungi (Basel) 7(4): 315. https://doi.org/ 10.3390/jof7040315 
3. Deng YZ, Naqvi NI (2019) Metabolic basis of pathogenesis and host adaptation in rice blast. Annu Rev Microbiol 73:601-619. https://doi.org/10.1146/annurev-micro-020518-115810

4. Feng X, Lin K, Zhang W, Nan J, Zhang X, Wang C, Wang R, Jiang G, Yuan Q, Lin S (2019) Improving the blast resistance of the elite rice variety Kongyu- 131 by updating the pi21 locus. BMC Plant Biol 19(1):249. https://doi.org/10.1186/s12870-019-1868-x

5. Huang X, Ren J, Li P, Feng S, Dong P, Ren M (2021) Potential of microbial endophytes to enhance the resistance to postharvest diseases of fruit and vegetables. J Sci Food Agric 101(5):1744-1757. https://doi.org/10.1002/jsfa.10829

6. Jing R, Li N, Wang W, Liu Y (2020) An endophytic strain JK of genus Bacillus isolated from the seeds of super hybrid rice (Oryza sativa L., Shenliangyou 5814 ) has antagonistic activity against rice blast pathogen. Microb Pathog 147: 104422. https://doi.org/ 10.1016/j.micpath.2020.104422

7. Khalaf EM, Raizada MN (2018) Bacterial seed endophytes of domesticated cucurbits antagonize fungal and oomycete pathogens including powdery mildew. Front Microbiol 9:42. https://doi.org/10.3389/fmicb.2018.00042

8. Liu Y, Wang R, Cao Y, Chen C, Bai F (2016) Identification and antagonistic activity of endophytic bacterial strain Paenibacillus sp. 5 L8 isolated from the seeds of maize (Zea mays L., Jingke 968). Ann Microbiol 66:653-660. https://doi.org/10.1007/s13213-015-1150-x

9. Matsumoto H, Fan X, Wang Y, Kusstatscher P, Duan J, Wu S, Chen S, Qiao K, Wang Y, Ma B, Zhu G, Hashidoko Y, Berg G, Cernava T, Wang M (2021) Bacterial seed endophyte shapes disease resistance in rice. Nat Plants 7(1):60-72. https://doi.org/10.1038/s41477-020-00826-5

10. Rangjaroen C, Lumyong S, Sloan WT, Sungthong R (2019) Herbicide-tolerant endophytic bacteria of rice plants as the biopriming agents for fertility recovery and disease suppression of unhealthy rice seeds. BMC Plant Biol 19(1): 580. https://doi.org/ 10.1186/s12870-019-2206-z

11. Rong S, Xu H, Li L, Chen R, Gao X, Xu Z (2020) Antifungal activity of endophytic Bacillus safensis B21 and its potential application as a biopesticide to control rice blast. Pestic Biochem Physiol 162:69-77. https://doi.org/10.1016/j.pestbp.2019.09.003

12. Shehata HR, Griffiths MW, Raizada MN (2017) Seeds of the wild progenitor of maize possess bacteria that antagonize foodborne pathogens. Foodborne Pathog Dis 14(4):202-209. https://doi.org/10.1089/fpd.2016.2225

13. Sun Z, Yang L, Zhang L, Han M (2018) An investigation of Panax ginseng Meyer growth promotion and the biocontrol potential of antagonistic bacteria against ginseng black spot. J Ginseng Res 42(3):304-311. https://doi.org/10.1016/j.jgr.2017.03.012

14. Tian X, Xu D, Sun T, Zhao S, Wang D (2020) Plant resistance and leaf chemical characteristic jointly shape phyllosphere bacterial community. World J Microbiol Biotechnol 36(9):139. https://doi.org/10.1007/s11274-020-02908-0

15. Yang F, Zhang R, Wu X, Xu T, Ahmad S, Zhang X, Zhao J, Liu Y (2020) An endophytic strain of the genus Bacillus isolated from the seeds of maize (Zea mays $L$.) has antagonistic activity against 
maize pathogenic strains. Microb Pathog 142: 104074. https://doi.org/10.1016/j.micpath. 2020.104074

Figures

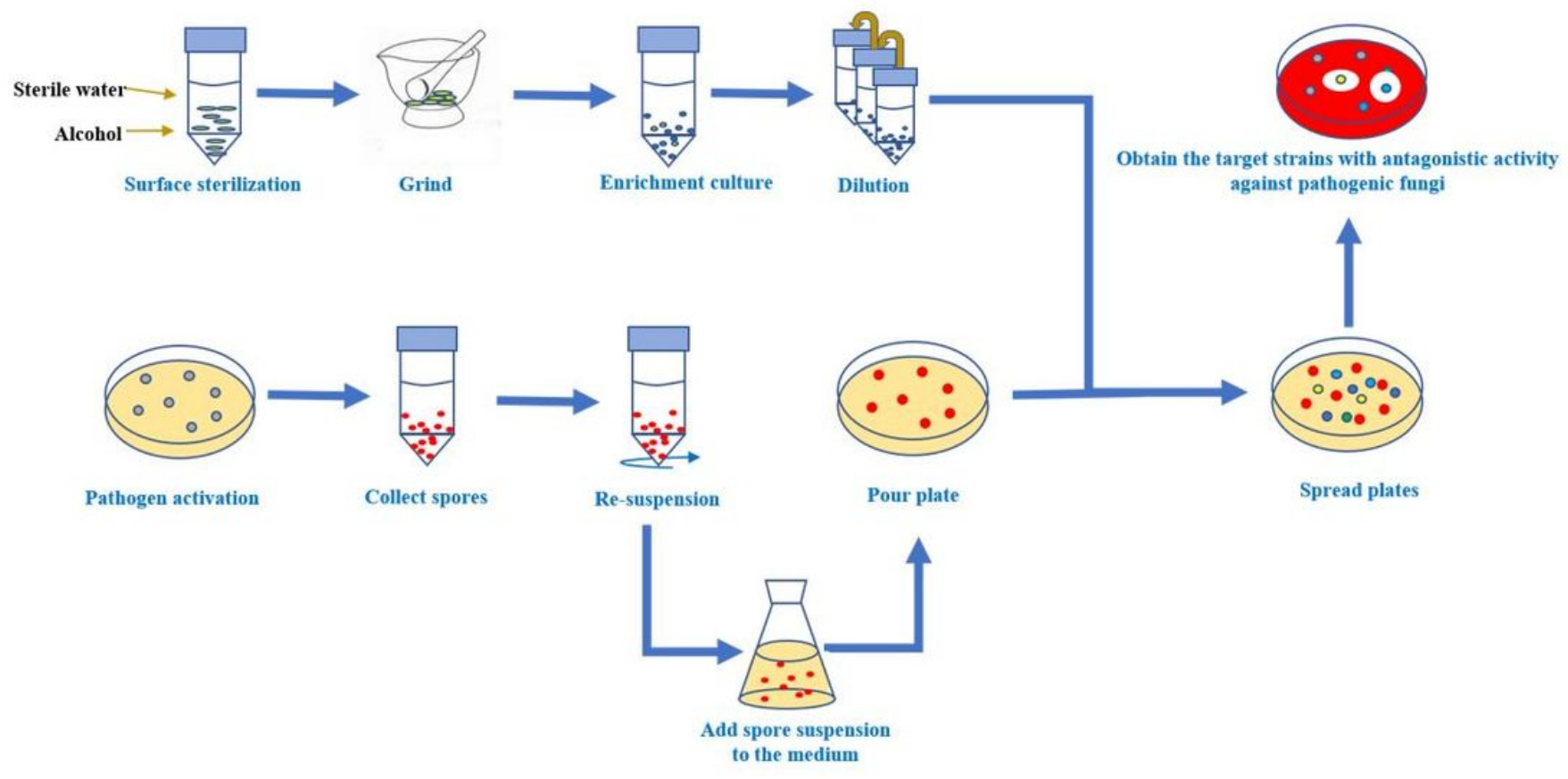

\section{Figure 1}

High-throughput screening of endophytes with antagonistic activity against Magnaporthe oryzae in rice seeds 


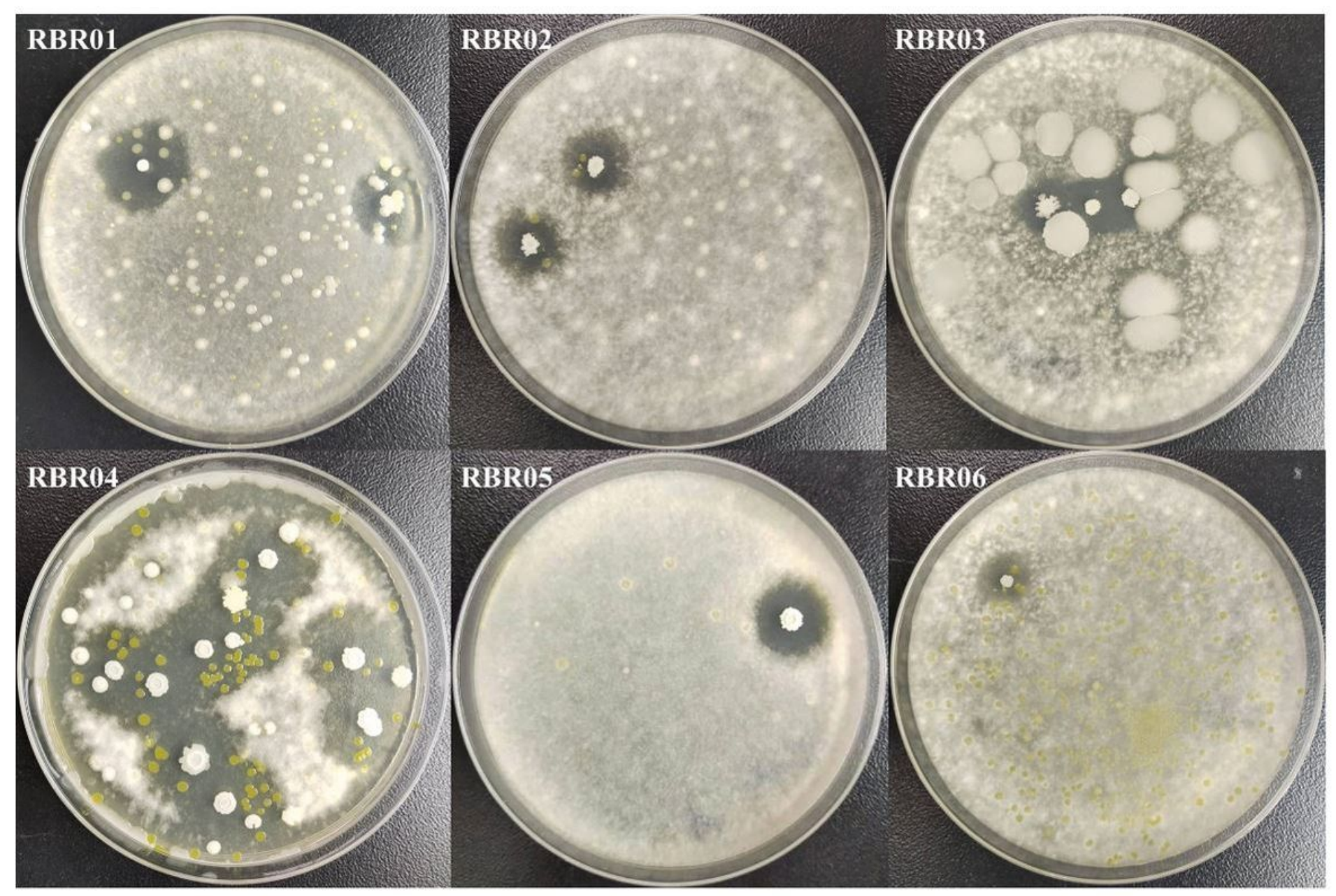

Figure 2

Screening of endophytic bacteria with antagonistic activity against M. oryzae in rice seeds by high throughput screening 